\title{
Neurological consequences of COVID-19: what have we learned and where do we go from here?
}

\author{
Abbas Jarrahi ${ }^{1 \dagger}$, Meenakshi Ahluwalia ${ }^{2 \dagger}$, Hesam Khodadadi ${ }^{3}$, Evila da Silva Lopes Salles ${ }^{3}$, Ravindra Kolhe ${ }^{2}$, \\ David C. Hess ${ }^{4}$, Fernando Vale ${ }^{1}$, Manish Kumar ${ }^{5}$, Babak Baban ${ }^{3}$, Kumar Vaibhav $^{1}$ and Krishnan M. Dhandapani ${ }^{1^{*}}$
}

\begin{abstract}
The coronavirus disease-19 (COVID-19) pandemic is an unprecedented worldwide health crisis. COVID-19 is caused by SARS-CoV-2, a highly infectious pathogen that is genetically similar to SARS-CoV. Similar to other recent coronavirus outbreaks, including SARS and MERS, SARS-CoV-2 infected patients typically present with fever, dry cough, fatigue, and lower respiratory system dysfunction, including high rates of pneumonia and acute respiratory distress syndrome (ARDS); however, a rapidly accumulating set of clinical studies revealed atypical symptoms of COVID-19 that involve neurological signs, including headaches, anosmia, nausea, dysgeusia, damage to respiratory centers, and cerebral infarction. These unexpected findings may provide important clues regarding the pathological sequela of SARS-CoV-2 infection. Moreover, no efficacious therapies or vaccines are currently available, complicating the clinical management of COVID-19 patients and emphasizing the public health need for controlled, hypothesisdriven experimental studies to provide a framework for therapeutic development. In this mini-review, we summarize the current body of literature regarding the central nervous system (CNS) effects of SARS-CoV-2 and discuss several potential targets for therapeutic development to reduce neurological consequences in COVID-19 patients.
\end{abstract}

Keywords: SARS-CoV-2, ARDS, Neurotropism, Coronavirus, Coagulopathy, Neutrophil extracellular traps, Stroke, Cytokine storm, Neuroinflammation

\section{Introduction}

A series of pneumonia cases of unknown origin emerged in December 2019 at Wuhan, China, resembling the recent severe acute respiratory syndrome coronavirus (SARS-CoV) and Middle East respiratory syndrome coronavirus (MERS-CoV) outbreaks [1-5]. Genetic sequencing of samples derived from infected patients subsequently identified the pathogen as a novel

\footnotetext{
* Correspondence: kdhandapani@augusta.edu

${ }^{\dagger}$ The authors Abbas Jarrahi and Meenakshi Ahluwalia contributed equally and should be considered co-first authors.

'Department of Neurosurgery, Medical College of Georgia, Augusta University, 1120 15th Street, 30912 Augusta, Georgia

Full list of author information is available at the end of the article
}

coronavirus, initially named 2019 novel coronavirus (2019-nCoV), with the associated disease called coronavirus disease-19 (COVID-19) [6]. Given the genetic similarity to SARS-CoV, the nomenclature of the novel coronavirus was later revised to severe acute respiratory syndrome coronavirus 2 (SARS-CoV-2) by the International Committee on Taxonomy of Viruses. Coronaviruses, enveloped positive-sense RNA viruses belonging to family Coronaviridae and the order Nidovirales, are widely infectious across species [7]. Indeed, SARS-CoV2 is believed to have a zoonotic origin and is $96 \%$ genetically similar to RaTG13, a previously described bat coronavirus [8]. The highly contagious and virulent nature of SARS-CoV-2 is evidenced by approximately 30,000,

(c) The Author(s). 2020 Open Access This article is licensed under a Creative Commons Attribution 4.0 International License, which permits use, sharing, adaptation, distribution and reproduction in any medium or format, as long as you give appropriate credit to the original author(s) and the source, provide a link to the Creative Commons licence, and indicate if changes were made. The images or other third party material in this article are included in the article's Creative Commons licence, unless indicated otherwise in a credit line to the material. If material is not included in the article's Creative Commons licence and your intended use is not permitted by statutory regulation or exceeds the permitted use, you will need to obtain permission directly from the copyright holder. To view a copy of this licence, visit http://creativecommons.org/licenses/by/4.0/ The Creative Commons Public Domain Dedication waiver (http://creativecommons.org/publicdomain/zero/1.0/) applies to the data made available in this article, unless otherwise stated in a credit line to the data. 
000 documented cases and 1,000,000 deaths worldwide, creating a global pandemic that has inflicted economic damage on an unprecedented scale.

The SARS-CoV-2 outbreak has generated immense interest from both the medical community and the general public in understanding the biology, epidemiology, and clinical characteristics, as evidenced by the appearance of over 54,000 peer-reviewed research articles in PubMed focused on COVID-19. SARS-CoV-2 exhibits crossover symptomology with two commonly circulating human coronaviruses (HCoV-NL63, HCoV-HKU1) and prior infection with these strains may greatly impact patient outcomes during the present pandemic. Much of the initial knowledge informing the response to the current SARS-CoV-2 outbreak was gained during the SARS-CoV and MERS-CoV outbreaks. SARS-CoV was first reported in Asia in 2003, spreading to North America, South America, and Europe, which infected over 8000 people worldwide and caused nearly 800 deaths. The subsequent MERS-CoV outbreak was associated with a mortality rate of $37 \%$, with most victims exhibiting one or more comorbid conditions. Likewise, the most characteristic clinical symptoms of COVID-19 patients are fever, fatigue, dry cough, myalgia, headache, dizziness, abdominal pain, diarrhea, nausea, and vomiting. More severe cases involve respiratory distress, which may require admittance to the intensive care unit and use of a ventilator [9]. Patients with underlying comorbidities such as hypertension, diabetes, cardiovascular disorders (CVD), and cerebrovascular diseases are more vulnerable to infection and exhibit a higher rate of hospitalization [9].

In addition to the classical symptoms of a respiratory virus, increasing evidence suggests COVID-19 patients may present with a diversity of unanticipated neurological symptoms, such as headache, nausea, anosmia, ageusia, myalgia/fatigue, confusion, disorientation, and vomiting [10-12] (Fig. 1). Human coronavirus ( $\mathrm{HCoV})$ infections are not restricted to the respiratory tract, with RNA from two HCoV strains (229E, OC43) detected in human brain autopsy samples from neurologically disease patients. Moreover, inter-neuronal propagation and axonal transport may favor viral invasion into the central nervous system (CNS) [11, 13, 14]. Indeed, olfactory and gustatory deficits are regarded as early symptoms of SARS-CoV-2 infection. Of particular interest, reports of ischemic strokes in younger, asymptomatic patients without comorbidities are appearing in the scientific

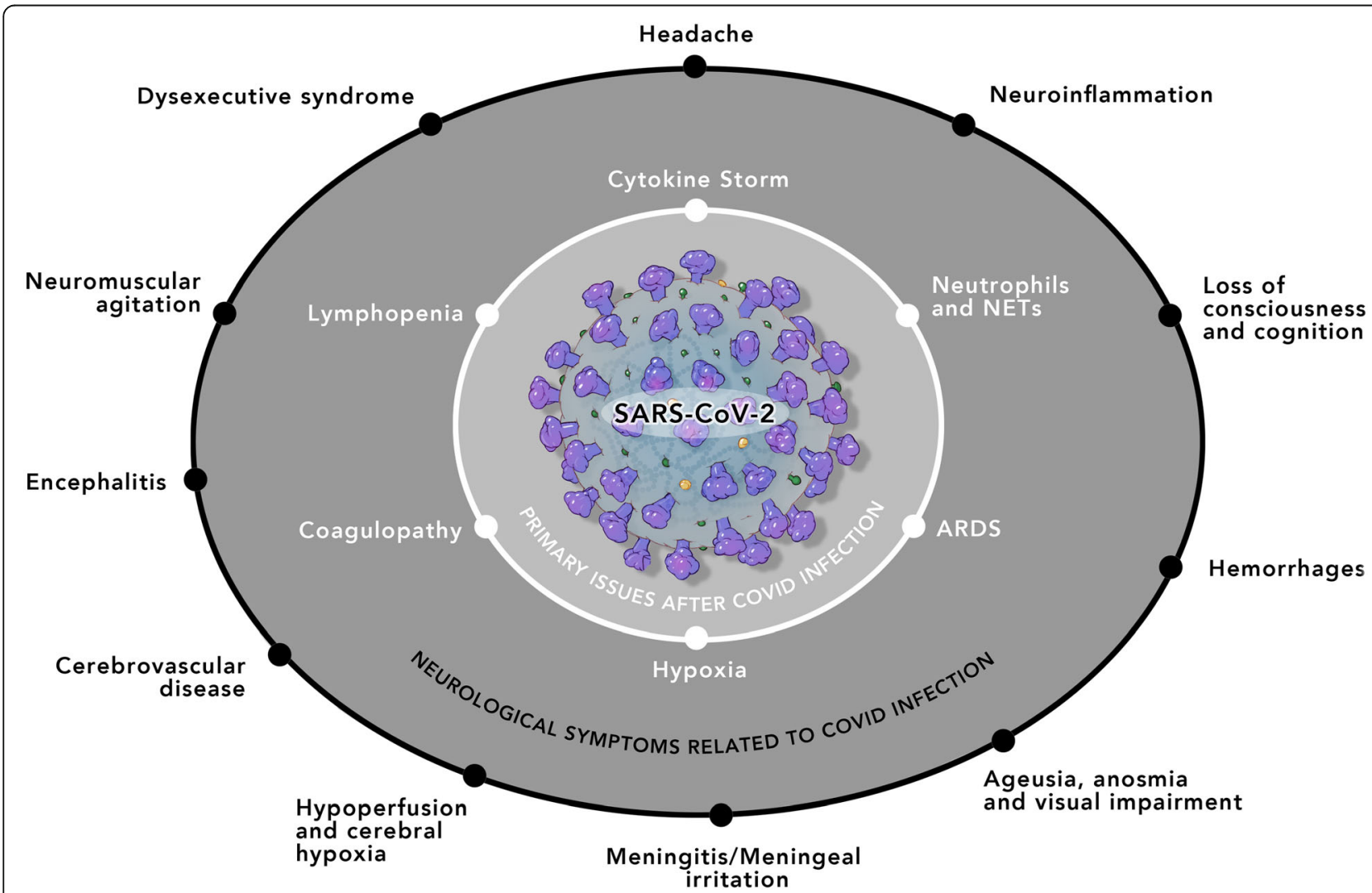

Fig. 1 Schematic illustration of COVID-19-related symptoms. Primary issues associated with COVID-19 are shown within the inner circle (see white text). These symptoms are widely reported in a large majority of patients infected with SARS-CoV-2. The outer circle (see black text) depicts neurological issues/symptoms that have been reported after COVID-19 
literature, even after the infection has seemingly resolved [15-17]. These limited case reports suggest the need for a deeper understanding of SARS-CoV-2 infection, including elucidation of how the CNS may be affected. Larger clinical studies will undoubtedly shed new light on the clinical manifestations of COVID-19 infection in the brain; however, in this mini-review, we summarize what is currently known regarding SARS-CoV-2-mediated neurological injury to establish a framework for future pre-clinical and clinical investigations. We discuss evidence supporting both hematogenous and retrograde neuronal dissemination of SARS-CoV-2 invasion into the CNS, including secondary neuropathologies, and highlight potential therapeutic approaches for future exploration.

\section{Neurological manifestations in COVID-19 patients}

As COVID-19 rapidly spread throughout the world, anecdotal reports of neurological issues emerged. An internet-based, cross-sectional study found 59 COVID19 patients from a study population of 1480 patients exhibiting influenza-like symptoms. Notably, loss of smell (68\% of COVID-19 patients) and gustatory impairments (71\% of COVID-19 patients) were distinguishing features of SARS-CoV-2 infection [10]. In line with this finding, approximately one-third of COVID-19 patients reported a loss of smell. Likewise, headache (about 8\%) and nausea and vomiting (1\%) were apparent in COVID-19 patients $[9,11,13]$. In addition, case studies of a 24-year-old male infected with SARS-CoV-2 in Japan presented with a fever and meningitis/meningeal irritation [18] while an infected 56-year-old male also was diagnosed with encephalitis [19]. In another case study, a 29-year-old woman diagnosed with COVID-19 presented with a left temporoparietal hemorrhagic venous infarction with transverse sigmoid sinus thrombosis on the left side [20]. These observational reports suggesting CNS involvement in the course of COVID-19 identified many interesting, yet unexplored, avenues for physicians and neuroscientists.

In a study in Strasbourg, France, neurological function was assessed in 58 COVID-19 patients with acute respiratory distress syndrome (ARDS) that were admitted into the intensive care unit (ICU) [12]. Neurological abnormalities were observed in $14 \%$ (8/58 patients) upon admission to the ICU, while $67 \%(39 / 58)$ showed neurological signs along with $69 \%(40 / 58)$ who showed agitation following termination of sedation or a neuromuscular blocker [12]. Further, $45 \%$ (26/58) of patients showed confusion and corticospinal tract signs were evident in 67\% (39/58) of admitted patients. Moreover, 13 patients $(22.41 \%)$ showing encephalopathic features exhibited leptomeningeal enhancement $(8 / 13)$ and bilateral frontotemporal hypoperfusion (11/13) on magnetic resonance imaging (MRI). Electroencephalography revealed diffuse bifrontal encephalopathy in one patient (1/8) [12]. Follow-up studies of 45 discharged patients revealed that 33\% (15/45) exhibited dysexecutive syndrome and showed signs of inattention, disorientation, and poorly organized movements and response [12].

A study of 214 COVID-19 patients from Wuhan, China, showed severe respiratory infections in $41 \%$ (88/ 214 ) of patients, with $36 \%$ (78/214) of patients displaying diverse neurologic signs, including loss of smell and taste, neuropathic pain, seizures, and strokes [21]. Indeed, loss of smell and taste were similarly reported in COVID-19 patients worldwide [10]. To better understand the neurological manifestations of COVID-19, symptoms were broadly categorized into three categories: skeletal muscular injury indexes, CNS indexes (e.g., acute cerebrovascular disease, headache, dizziness, impaired consciousness, seizure, and ataxia), and peripheral nervous system indexes (nerve pain, impaired taste, smell, or vision). Of the 78 patients displaying neurological abnormalities, $25 \%$ showed symptoms related to CNS dysfunction, $11 \%$ showed issues related to skeletal muscle injury, and 9\% exhibited issues with peripheral nervous system (PNS) function [21]. Of note, neurological symptoms were more commonly observed in older patients (mean age $=59.2$ years), in patients with more severe infection, and in patient with pre-existing conditions, such as hypertension, diabetes, malignancy, or cardiac/cerebrovascular disease. Importantly, most of the neurological consequences of COVID-19 were apparent within the first 2 days of infection, although cerebrovascular events and impaired consciousness were often delayed beyond this acute time period and associated with the increased mortality rate [21].

A case study in January 2020, identified a 61-year-old woman that presented with acute weakness in both legs, and severe, progressive fatigue within 1 week after traveling to Wuhan, China. Of note, the observed neurological symptoms and subsequent diagnosis of Guillain-Barre syndrome (GBS) occurred several days prior to the development of respiratory symptoms and before a positive PCR test for SARS-CoV-2 [22]. Similarly, a 67-year-old female patient with a history of breast cancer presented in New York City with rapidly progressive quadriparesis, lower back pain, paresthesias, and urinary retention, diagnosed as severe, rapidly progressing GBS [23]. Moreover, several reports have emerged showing an acute GBS in pediatric patients infected with SARS-CoV-2 [24, 25]. While an association between SARS-CoV-2 infection and symptoms of GBS is evident [26], it remains unclear whether GBS manifestation is a coincidental presentation during SARS$\mathrm{CoV}-2$ infection or whether this represents a causative relationship. 


\section{How does SARS-CoV-2 directly affect brain function?}

The previous section detailed a number of international studies that clearly established the nervous system as a target of COVID-19 infection. These early-stage clinical reports illustrate the need for an improved mechanistic understanding of how SARS-CoV-2 affects neurological function. This knowledge will be essential for the development of efficacious therapies to alleviate suffering in affected individuals. In this section, we propose several mechanisms to explain how a respiratory virus afflicts the CNS.

\section{Is SARS-CoV-2 neurotropic?}

A simple explanation for the neurological effects of COVID-19 is direct viral entry and infection of the CNS. Epidemiological data show a latency of up to 1 week between the initial infection and hospital admittance for COVID-19 patients $[9,21]$, providing a window for potential viral entry into the CNS. Neurotropism is commonly observed in coronaviruses, with neuro-invasive properties well documented in SARS-CoV, MERS-CoV, $\mathrm{HCoV}-229 \mathrm{E}, \mathrm{HCoV}-\mathrm{OC} 43$, and porcine hemagglutinating encephalomyelitis coronavirus (PHE) [11, 13, 27, 28]. The SARS-CoV-2 spike protein also alters barrier function in human models of the blood-brain barrier, providing an additional mechanism of potential CNS entry [29]. Given the genetic similarity and conserved viral structure with SARS-CoV, it appears likely that SARSCoV-2 may also exhibit neurotropic properties [30, 31].

Tissue distribution of host receptors is generally believed to decide the tropisms of viruses [32-34]. In contrast to MERS-CoV, which exploits dipeptidyl peptidase 4 (DPP4) to evade host cells [35, 36], the densely glycosylated spike protein of SARS-CoV-2 virus binds with high affinity to the type I transmembrane metallocarboxypeptidase, angiotensin-converting enzyme 2 (ACE2), providing a mechanism of viral entry into human cells that mirrors the entry point for SARS-CoV [8, 37-41]. ACE2, which negatively regulates the renin-angiotensin-aldosterone system by degrading angiotensin II to generate angiotensin $1-7$, is required to lower blood pressure and as such, is a frequent target for anti-hypertensive drug development [40, 42-46]. Other functions of ACE2 include the metabolism of apelin-13, neurotensin, kinetensin, dynorphin, [des-Arg ${ }^{9}$ ]-bradykinin, and [Lys-des-Arg ${ }^{9}$ ]-bradykinin [47]. ACE2 is widely expressed in airway epithelium, lung parenchyma, vasculature, kidney, heart, and the gastrointestinal tract $[48,49]$, primary sites of infection by SARS-CoV and SARS-CoV-2; however, it is interesting to note that ACE2-expressing endothelial cells and human intestinal cells were unaffected by SARS-CoV $[50,51]$, while ACE2 negative hepatocytes were susceptible to SARS-CoV infection [32]. Thus, the expression of ACE2 alone may not be sufficient for host cell infection by SARS-CoV-2.
Initial studies failed to observe ACE2 expression in the brain [48, 49]; yet, RT-PCR studies detected low levels of ACE2 mRNA expression in the human brain while subsequent studies revealed that ACE2 immunoreactivity was exclusively within brain endothelial and smooth muscle cells [52]. ACE2 expression is also reported in both neurons and glia [53, 54], suggesting the brain may be a potential target of SARS-CoV-2. Consistent with the possibility of direct CNS infection, SARS-CoV-2 RNA was detectable in the cerebrospinal fluid (CSF), but not in a nasopharyngeal swab from a 24-year-old COVID-19 patient presenting with seizures, hippocampal atrophy, and pan-paranasal sinusitis that was subsequently diagnosed with viral meningitis [18]. Similarly, a 56-year-old encephalitis patient exhibiting reduced consciousness had detectable SARS-CoV-2 in the CSF. These findings in COVID-19 patients are in agreement with reports showing $\mathrm{HCoV}-\mathrm{OC} 43 \mathrm{RNA}$ in the CSF of a 15-year-old acute demyelinating encephalomyelitis patient [55], whereas SARS-CoV was detected in the serum and CSF from SARS patients with persistent epilepsy [56]. Therefore, the capacity to leave the respiratory tract and potentially infect other tissues may be a defining feature of CoVs.

\section{Does SARS-CoV-2 use a trans-synaptic mechanism of CNS infection?}

CoVs may enter the CNS via retrograde neuronal diffusion, potentially via the cribriform plate of the ethmoid bone [57]. In mice, ACE2 and TMPRSS2, a protease that contributes toward the spread of CoVs [58], were expressed in sustentacular cells of the olfactory epithelium, with a more pronounced expression in aged mice [59]. SARS-CoV and MERS-CoV were observed within the CNS, raising the possibility of trans-synaptic viral spread via peripheral nerve terminals as a possible mechanism whereby $\mathrm{CoVs}$ may gain access to the CNS [27, 28, 60-62]. SARS-CoV particles were observed in $\mathrm{CNS}$ neurons and brain samples from patients diagnosed with SARS [62-64] while other CoVs, including HEV67 and avian bronchitis virus utilized transsynaptic transfer [27, 28, 61]. Transgenic mice expressing human DPP4 (hDPP4) under the control of the surfactant protein $\mathrm{C}$ or cytokeratin-18 promoter showed a progressive fatal course that was paralleled by high viral titers in thalamus and brain stem within 2-6 days after intranasal administration of MERS-CoV [65]. Similarly, lethal intranasal inoculation of SARS-CoV in transgenic mice expressing human ACE2 (hACE2) in the airway and other epithelia resulted in pro-inflammatory activation and the presence of the virus within the olfactory bulb, thalamus, and brain stem via postulated spread through the olfactory nerves [66]. Following the viral entry into the CNS, infection rapidly spread via a trans-neuronal route to other connected brain regions, culminating in mortality due to neuronal loss 
in the cardiorespiratory centers within the medulla [67]. Finally, SARS was associated with delayed olfactory neuropathy while the loss of olfactory function is an internationally reported symptom of COVID-19, with some patients showing bilateral obstructive inflammation of the olfactory clefts correlating with impaired olfaction [68-71]. Thus, retrograde trans-synaptic transport from the lung and lower respiratory airways to the medullary cardiorespiratory centers of the brain and the olfactory centers may mediate the progressive acute respiratory failure and anosmia in COVID-19 patients.

Beyond trans-synaptic spread from the respiratory system, another possibility is movement via the brain-gut axis. The gastrointestinal (GI) tract is directly infected by SARS-CoV-2 and up to a quarter of COVID-19 patients display GI issues, including nausea, anorexia, vomiting, and diarrhea [72, 73]. A temporal correlation exists between GI and neurological symptoms, and it is postulated that anorexia and nausea may be caused, at least in part, by infection of the lateral hypothalamic nuclei $[73,74]$. Toward this end, SARS-CoV-2 may enter the CNS via the vagus nerve, a cranial nerve that regulates parasympathetic control of the heart, lungs, and GI tract.

In addition to direct neuronal entry, SARS-CoV-2 may infect non-neuronal cell types to produce neurological complications. The SARS-CoV-2 entry genes, ACEs and TMPRSS2, are detectable in non-neuronal cell types in the olfactory epithelium and olfactory bulb [75]. Thus, infection of glia and vascular cells could contribute toward hypoperfusion, local inflammation, and cytokine release, loss of function of supporting cells, or damage to sustentacular and Bowman's gland cells to induce olfactory neuronal dysfunction or death [68, 76-78]. Future studies surely will shed new light on these mechanisms of CNS spread, which may have significant implications for the future treatment of $\mathrm{CoV}$-infected patients.

\section{Does immune activation contribute to neurological dysfunction after $\mathrm{CoV}$ infections?}

Inflammation is the first line of defense against pathogens. The innate immune system provides an early mechanism of host protection by producing type I interferons (IFN), complement proteins, and chemokines/cytokines to limit viral infection $[79,80]$. While a robust innate immune response is necessary to elicit protective adaptive immunity, a prolonged and/or overactive immune response contributes toward pathological tissue injury [81]. Interestingly, pre-clinical studies showed that excess cytokine release after SARS-CoV infection dampened adaptive immunity [82]. In line with this observation, despite an increase in leukocyte activation and massive release of pro-inflammatory cytokines, SARS-
CoV-2 infection is associated with lymphopenia, including suppression of both $\mathrm{CD}^{+}$and $\mathrm{CD} 8^{+} \mathrm{T}$ cells as well as the increased appearance of exhausted T cells [83-85]. Given this progression, significant attention has been focused on the development of a "cytokine storm," the rapid pathological release of excess cytokines, which is associated with high fever, respiratory distress, multi-organ failure, and increased mortality over the first 2 weeks in COVID-19 patients [86].

\section{Cytokine storm}

Critically ill COVID-19 patients exhibited an increased ratio of white blood cells/lymphocytes and higher plasma levels of C-reactive protein (CRP), IL-2, IL-7, IL10, GSCF, IP10 (CXCL10), MCP-1 (CCL2), MIP-1 $\alpha$ (CCL3), and TNF- $\alpha$, as compared to non-ICU patients $[9,87]$. Inflammatory cytokines, such as IL-6, IL-10, and TNF- $\alpha$, are elevated following infection with SARS-CoV2 and are believed to orchestrate a cytokine storm [84]. Given these appreciated detrimental effects, a number of clinical trials using tocilizumab, an IL-6 receptor antagonist (NCT04306705, NCT04322773); sarilumab, a IL-6 receptor antagonist (NCT04322773, NCT04315298); or clazakizumab, an IL-6 neutralizing antibody (NCT04343989; NCT04348500), were initiated as potential therapies to limit the cytokine storm in COVID-19 patients.

In contrast to the established association between the cytokine storm and respiratory distress in COVID-19 patients, relatively less is known about the lasting neurological effects of these events. The CNS is regarded as an immuneprivileged organ, yet the brain is highly vulnerable to inflammatory mediators and tissue hypoxia [88-91]. Infectious encephalitis is an inflammation of the brain that may develop in bacteria- or virus-infected children, elderly, and immuno-compromised individuals. While mild encephalitis produces transient flu-like symptoms, including fever, headache, seizures, light sensitivity, neck stiffness, and loss of consciousness, more severe cases can produce confusion, psychosis, limb weakness, double vision, cognitive impairments, speech and hearing deficits, coma, and increased fatality. During the course of COVID-19 infection, reports of a rare condition, acute necrotizing hemorrhagic encephalopathy, emerged in patients showing intracranial cytokine storm syndrome without direct viral invasion [92]. Radiological imaging of acute necrotizing hemorrhagic encephalopathy indicates lesions within the thalamus, brain stem, and cerebral white matter [93], suggesting the likely need for neurological assessments of COVID-19 patients. In addition, cytokine-induced pulmonary injury during ARDS may adversely affect brain function due to the intimate association between the lungs and the respiratory centers in the medulla and pons of the brain stem [94-97]. Thus, the neurological manifestations of COVID-19 may be 
secondary to the consequences of ARDS-mediated inflammation and hypoxemia/hypoxia [94, 95]. As clinical data becomes more widely available regarding the link between the nervous and respiratory systems, this knowledge will greatly shape further pre-clinical efforts.

\section{Immunomodulatory therapies to manage the neurological complications from SARS-CoV-2}

Understanding the immune dysregulation in patients with COVID-19 will provide a greater understanding of SARS-CoV-2 pathogenesis. The detrimental impact of unrestrained immune activation and the cytokine storm are clearly evident, but therapeutic targets beyond antiviral drugs remain a major obstacle to limiting neurological injury secondary to COVID-19. As a significant member of the pattern recognition receptor (PRR) family, Toll-like receptors (TLRs) play a crucial role in the initiation of immune responses against viral infections. In addition to initiating the intracellular response to viral RNA, TLRs induce signaling cascades and activate transcription factors that shape the cellular response to infection. Along these lines, activation of TLRs mobilize and recruit innate immune cells (e.g., neutrophils, monocytes, innate lymphoid cells) and induce cytokines and chemokines that limit viral progression and activate acquired immunity [98]. Of the TLRs, TLR3, which is expressed in both immune and non-immune cells, recognizes double-stranded RNA (CoVs are doublestranded RNA viruses). Upon activation, TLR3 induces interferon regulatory transcription factor 3 (IRF3) to stimulate the production of type I interferons as a host defense mechanism against viruses [99]. Importantly, mounting evidence suggests that TLR3 may initiate the cytokine storm and drive systemic inflammatory responses [100-102]. Thus, TLR3 may represent a target for immunotherapeutic modulation to limit neurological dysfunction in COVID-19 patients [103].

\section{Do coagulopathies contribute to the neurological consequences of COVID-19?}

COVID-19 patients frequently exhibit complications associated with coagulopathy, including venous thromboembolism, acute coronary syndrome, myocardial infarction, and cerebral infarction [104-107]. SARSCoV-2 infection was associated with prolonged prothrombin time, platelet abnormalities, elevated levels of D-dimer, increased fibrinogen/fibrin degradation products, and sepsis-induced coagulopathy (SIC), a form of disseminated intravascular coagulation (DIC), which was observed in the majority of COVID-19-related deaths [108, 109]. Severe COVID-19 patients exhibit hypoxia, a risk factor that increases thrombosis via activation of hypoxia-inducible transcriptional regulation and by increasing blood viscosity [110]. Given the role of coagulopathy, administration of anticoagulants were postulated as a treatment for severe COVID-19 patients $[106,109]$; however, anticoagulation did not reduce lifethreatening thrombotic complications in a recent multicenter prospective cohort study of 150 COVID-19 patients with ARDS [105], suggesting the need for extensive research to identify alternative targets for therapeutic intervention.

With respect to the CNS, cytokine release, encephalopathy, and onset of ischemic stroke symptoms are correlated in COVID-19 patients [111, 112]. Inflammation and coagulation are inextricably linked processes that exhibit reciprocal cross-talk [113]. Systemic inflammation activates coagulation mechanisms by driving tissue factor-mediated thrombin generation and inhibiting endogenous fibrinolysis. In turn, activation of the coagulation system may influence inflammatory activity and contribute toward the development of hemorrhagic fever and thrombotic microangiopathy. While a clear association exists between SARS-CoV-2 and stroke incidence, it remains unanswered whether coagulation, secondary to COVID-19 infection, is an initiating factor for ischemic stroke or whether the immune response in response to the viral infection worsens the severity of a stroke. In support of the former possibility, elevated inflammation may heighten the risk of developing an acute ischemic stroke in the elderly, potentially via modulation of the coagulation cascade, whereas the latter possibility may be explained by exacerbation of the post-stroke inflammatory response [114-117]. While it is clear that COVID-19 patients exhibiting pro-thrombotic and/or pro-inflammatory activation may require neurological evaluation, further clinical data and pre-clinical research are needed to define the mechanistic link between SARS-CoV-2 and stroke outcomes.

Given the limited efficacy of broad anticoagulants in COVID-19 patients, alternative therapeutic targets are needed to reduce the detrimental effects of coagulopathies. Neutrophils are circulating innate immune cells that rapidly mobilize to phagocytose pathogens as a mechanism of host protection after an infection. An elevated neutrophil-to-lymphocyte ratio was an independent risk factor for mortality in hospitalized COVID-19 patients [118-120]. Recent evidence suggests that activated neutrophils also may extrude a meshwork of chromatin fibers into the extracellular space to form cloud-like neutrophil extracellular traps (NETs), which may function as a mechanism of pathogen trapping. Extensive infiltration of neutrophils into the pulmonary capillaries of COVID-19 patients was associated with fibrin deposition and vascular lesions in the absence of sepsis while elevated neutrophil counts were associated with ocular dysfunction during SARS-CoV-2 infection [121-125]. Moreover, NETs, which stimulate pro-inflammatory responses in human airway 
epithelial cells [126], are present in many pulmonary diseases, including asthma, chronic obstructive pulmonary disease (COPD), cystic fibrosis, respiratory syncytial virus bronchiolitis, influenza infection, bacterial pneumonia, ARDS, and tuberculosis [127-132]. While the extent of neutrophil priming and NET formation in ARDS patients correlated with disease severity and mortality [130, 133-136], the clinical significance of NETs in the pathophysiology of COVID-19 remains undefined.

Sera from COVID-19 patients displayed elevated levels of cell-free DNA, myeloperoxidase-DNA complexes, and citrullinated histone $\mathrm{H} 3$, suggesting NET formation and raising the possibility that NETs may provide a potential target for intervention in COVID-19 patients [121, 137]. Interestingly, in addition to roles in host defense against viruses and bacteria, NETs also provide a scaffold for thrombogenesis $[138,139]$. Indeed, impaired degradation of NETs is clinically associated with acute thrombotic microangiopathies [140], while the presence of citrullinated histone $\mathrm{H} 3$, a biomarker of NET formation, within thrombi retrieved from acute ischemic stroke patients was independently associated with patient mortality $[141,142]$. Of interest, we recently reported that elevated NET formation was associated with microvascular occlusion and cerebral hypoperfusion after acute brain injury in both mice and humans [143]. Conversely, administration of recombinant human DNase-I, an FDA-approved drug under investigation for the management of COVID-19-induced ARDS [144], improved blood flow and outcomes after both experimental stroke and traumatic brain injury [143, 145-147]. Thus, the widespread generation of NETs after SARS-CoV-2 may provide a potential target to reduce acute and chronic neurological consequences, including headache, elevated stroke risk, and potential cognitive issues due to COVID-19.

\section{Challenges for the clinical management of COVID-19}

A number of medications are being investigated in COVID-19 management, including remdesivir, lopinavir/ritonavir combination, HIV protease inhibitors, chloroquine, and hydroxychloroquine, which may inhibit viral replication in the early stages of infection [148]. In addition, immune-based approaches, such as convalescent plasma, SARS-CoV-2 immunoglobulins, nonspecific intravenous immunoglobulins (IVIG), and mesenchymal stem cells, as well as immunomodulatory medications such as corticosteroids (dexamethasone), interferons (IFN $\alpha$ and IFN $\beta$ ), interleukin inhibitors (IL-1 and IL-6 inhibitors), and kinase inhibitors (Bruton's tyrosine kinase or Janus kinase inhibitors) are frequently employed as treatment options [3]. On top of the neurological manifestations of SARS-CoV-2, many of these therapies potentially exhibit adverse neurological effects.
For example, chloroquine and hydroxychloroquine may be associated with neuropsychiatric adverse effects, retinopathy, ataxia, seizures, and limbic encephalitis [149] while ribavirin and interferons are linked to retinopathy and neuropsychiatric consequences [150]. Seizures a reported symptom of SARS-CoV-2 infection, even in patients with no past medical history of epilepsy; however, an increased occurrence of seizures may be an adverse effect of anti-viral medications (e.g., lopinavir, ritonavir, ribavirin) [151]. Thus, further research to distinguish the deleterious neurological consequences of SARS-CoV-2 from the neurological side effects of COVID-19 therapies is necessary to advance clinical care.

Several co-morbidities associated with neurological dysfunction, including obesity, high body mass index, diabetes, and hypertension correlate with increased rates of infection and worse COVID-19 patient outcomes [152-155]. Therefore, a unique challenge of managing SARS-CoV-2 will be managing the detrimental consequences of co-morbidities with the treatment of COVID-19. Administration of anticoagulants and statins may encounter drug interactions with the lopinavir/ritonavir combination used for COVID19 management [150]. Myasthenia gravis or Lambert-Eaton myasthenic syndrome patients receiving immunosuppressive therapy may display a more severe COVID-19 illness and require alternative treatments to avoid myasthenic crisis [156]. In such patients, the administration of IVIG may improve outcomes whereas hydroxychloroquine could worsen the myasthenic crisis [157]. A case report study of a relapsing-remitting multiple sclerosis (MS) patient with SARS-CoV2 infection reported a worsening of neurological symptoms at initial presentation [158]. While the current consensus is to continue disease-modifying treatments, SARS-CoV-2 infected MS patients may benefit from. interferon therapy, suggesting some alterations in the MS treatment regimen may enhance outcomes $[159,160]$.

Finally, there is a growing appreciation for the psychiatric effects of COVID-19. A comprehensive metaanalysis study of SARS or MERS cases revealed that infected patients exhibited confusion (27.9\% of cases), depression (32.6\%), anxiety (35.7\%), impaired memory $(34.1 \%)$, and insomnia (41.9\%) in the acute phase while post-traumatic stress (32.2\%), depression $(10.5 \%)$, insomnia (12.1\%), anxiety (12.3\%), irritability (12.8\%), and memory impairment (18.9\%) chronically persisted after recovery [161]. In line with these findings, COVID-19 patients under intensive care showed signs of delirium with confusion (65\%), agitations (69\%), and altered consciousness (21\%), while 33\% showed dysexecutive syndrome at discharge [161]. Therefore, a psychiatric evaluation of patients may be necessary during and beyond hospitalization, including into the chronic term as a possible neurological sequela of COVID-19. 


\section{Conclusions}

The COVID-19 pandemic, caused by the novel SARS$\mathrm{CoV}-2$ virus, is associated with a broad pathophysiology that has resulted in worldwide mortality and morbidity. While primarily regarded as a respiratory virus, SARSCoV-2 produces wide-ranging and often unpredictable neurological symptoms, ranging from anosmia to encephalitis to increased stroke risk (Fig. 1), that complicate clinical management. Improved development, validation, and implementation of rapid imaging techniques, such as MRI, may aid in early diagnosis and proactive intervention to limit long-term neurological consequences. Future research defining whether SARSCoV-2 exhibits neurotropism and/or initiates peripheral immune activation and hypercoagulation to affect brain function will be paramount for the development of efficacious therapies to mitigate the deleterious neurological consequences of COVID-19, including potential benefits in the management of acute respiratory failure. Finally, the incorporation of "-omics approaches" will be useful to identify patient populations at the highest risk for developing neurological symptoms. Undoubtedly, biological variables, including sex, age, comorbid conditions (e.g., hypertension, diabetes, stress), pre-existing neurological diseases, and other yet undefined genetic polymorphisms dictate the clinical course of SARS-CoV-2 infection. These unbiased, population-wide investigations will provide valuable information to guide clinical practice in the management of COVID-19, as well as to aid in the management of future pandemics.

\section{Acknowledgements}

The authors acknowledge the artwork prepared by Colby Zahn.

\section{Authors' contributions}

$\mathrm{AJ}, \mathrm{MA}, \mathrm{BB}, \mathrm{KV}$, and $\mathrm{KMD}$ drafted the manuscript. HK, ES, RK, DCH, FV, and MK provided intellectual input. All authors approved the final version of the manuscript.

\section{Funding}

The authors' research is supported by grants from the National Institutes of Health (R01NS110378 to BB/KMD, R01117565 to KMD, R01NS099455 to DCH, R01NS112511 to DCH, U01NS113356 to DCH, R01NS114560, and R03HD094606 to KV). The funding bodies had no role in the study, analysis, or data interpretation.

\section{Availability of data and materials}

Not applicable.

\section{Ethics approval and consent to participate}

Not applicable.

\section{Consent for publication}

All authors agree to publication in the current form.

\section{Competing interests}

The authors declare that they have no competing interests.

\section{Author details}

${ }^{1}$ Department of Neurosurgery, Medical College of Georgia, Augusta University, 1120 15th Street, 30912 Augusta, Georgia. ${ }^{2}$ Department of Pathology, Medical College of Georgia, Augusta University, Augusta, Georgia. ${ }^{3}$ Department of Oral Biology and Diagnostic Sciences, Dental College of
Georgia, Augusta University, Augusta, Georgia. ${ }^{4}$ Department of Neurology, Medical College of Georgia, Augusta University, Augusta, Georgia. ${ }^{5}$ Department of Allied Health Science, Shri B. M. Patil Medical College, Hospital and Research Centre, BLDE (Deemed to be University), Vijayapura, Karnataka, India.

Received: 5 June 2020 Accepted: 21 September 2020

Published online: 30 September 2020

\section{References}

1. Ksiazek TG, Erdman D, Goldsmith CS, Zaki SR, Peret T, Emery S, et al. A novel coronavirus associated with severe acute respiratory syndrome. New England journal of medicine. 2003;348(20):1953-66.

2. Kuiken $T$, Fouchier RA, Schutten M, Rimmelzwaan GF, Van Amerongen G, van Riel D, et al. Newly discovered coronavirus as the primary cause of severe acute respiratory syndrome. The Lancet. 2003;362(9380):263-70.

3. Drosten C, Günther S, Preiser W, Van Der Werf S, Brodt H-R, Becker S, et al. Identification of a novel coronavirus in patients with severe acute respiratory syndrome. New England journal of medicine. 2003;348(20):1967-76.

4. de Groot RJ, Baker SC, Baric RS, Brown CS, Drosten C, Enjuanes L, et al. Commentary: Middle East respiratory syndrome coronavirus (MERS-CoV): announcement of the Coronavirus Study Group. Journal of virology. 2013; 87(14):7790-2

5. Zaki AM, Van Boheemen S, Bestebroer TM, Osterhaus AD, Fouchier RA. Isolation of a novel coronavirus from a man with pneumonia in Saudi Arabia. New England Journal of Medicine. 2012;367(19):1814-20.

6. Del Rio C, Malani PN. COVID-19-new insights on a rapidly changing epidemic. JAMA. 2020;323(14):1339-40.

7. Richman DD, Whitley RJ, Hayden FG. Clinical virology: John Wiley \& Sons; 2016.

8. Zhou P, Yang XL, Wang XG, Hu B, Zhang L, Zhang W, et al. A pneumonia outbreak associated with a new coronavirus of probable bat origin. Nature. 2020;579(7798):270-3.

9. Huang C, Wang Y, Li X, Ren L, Zhao J, Hu Y, et al. Clinical features of patients infected with 2019 novel coronavirus in Wuhan, China. Lancet. 2020;395(10223):497-506.

10. Yan CH, Faraji F, Prajapati DP, Boone CE, DeConde AS. Association of chemosensory dysfunction and COVID-19 in patients presenting with influenza-like symptoms. International forum of allergy \& rhinology. 2020; 10(7):806-13.

11. Dubé M, Le Coupanec A, Wong AH, Rini JM, Desforges M, Talbot PJ. Axonal transport enables neuron-to-neuron propagation of human coronavirus OC43. Journal of virology. 2018;92(17):e00404-18.

12. Helms J, Kremer S, Merdji H, Clere-Jehl R, Schenck M, Kummerlen C, et al. Neurologic features in severe SARS-CoV-2 infection. N Engl J Med. 2020; 382(23):2268-70

13. Talbot PJ, Ékandé S, Cashman NR, Mounir S, Stewart JN. Neurotropism of human coronavirus 229E. Coronaviruses. 1994:339-46.

14. Arbour N, Day R, Newcombe J, Talbot PJ. Neuroinvasion by human respiratory coronaviruses. J Virol. 2000;74(19):8913-21.

15. Siepmann T, Sedghi A, Simon E, Winzer S, Barlinn J, de With K, et al. Increased risk of acute stroke among patients with severe COVID-19: a multicenter study and meta-analysis. Eur J Neurol. 2020.

16. Sweid A, Hammoud B, Bekelis K, Missios S, Tjoumakaris SI, Gooch MR, et al. Cerebral ischemic and hemorrhagic complications of coronavirus disease 2019. Int J Stroke. 2020:1747493020937189.

17. Sweid A, Hammoud B, Weinberg JH, Oneissi M, Raz E, Shapiro M, et al. Letter: thrombotic neurovascular disease in COVID-19 patients. Neurosurgery. 2020;87(3):E400-E6.

18. Moriguchi T, Harii N, Goto J, Harada D, Sugawara H, Takamino J, et al. A first case of meningitis/encephalitis associated with SARS-Coronavirus-2. International journal of infectious diseases: IJID: official publication of the International Society for Infectious Diseases. 2020;94:55-58.

19. Zhou L, Zhang M, Wang J, Gao J. Sars-Cov-2: underestimated damage to nervous system. Travel Med Infect Dis. 2020;36:101642.

20. Klein DE, Libman R, Kirsch C, Arora R. Cerebral venous thrombosis: a typical presentation of COVID-19 in the young. Journal of stroke and cerebrovascular diseases : the official journal of National Stroke Association. 2020;29(8):104989.

21. Mao L, Jin H, Wang M, Hu Y, Chen S, He Q, et al. Neurologic manifestations of hospitalized patients with coronavirus disease 2019 in Wuhan. China. JAMA neurology. 2020;77(6):683-90. 
22. Zhao H, Shen D, Zhou H, Liu J, Chen S. Guillain-Barre syndrome associated with SARS-CoV-2 infection: causality or coincidence? Lancet Neurol. 2020; 19(5):383-4.

23. Abrams RMC, Kim BD, Markantone DM, Reilly K, Paniz-Mondolfi AE, Gitman $M R$, et al. Severe rapidly progressive Guillain-Barre syndrome in the setting of acute COVID-19 disease. J Neurovirol. 2020.

24. Frank CHM, Almeida TVR, Marques EA, de Sousa MQ, Feitoza PVS, Borba MGS, et al. Guillain-Barre Syndrome associated with SARS-CoV-2 infection in a pediatric patient. J Trop Pediatr. 2020.

25. Khalifa M, Zakaria F, Ragab Y, Saad A, Bamaga A, Emad Y, et al. Guillain-Barre Syndrome associated with SARS-CoV-2 detection and a COVID-19 infection in a child. J Pediatric Infect Dis Soc. 2020.

26. Paybast S, Gorji R, Mavandadi S. Guillain-Barre Syndrome as a neurological complication of novel COVID-19 Infection: a case report and review of the literature. Neurologist. 2020;25(4):101-3.

27. Andries K, Pensaert M. Immunofluorescence studies on the pathogenesis of hemagglutinating encephalomyelitis virus infection in pigs after oronasal inoculation. American journal of veterinary research. 1980;41(9):1372-8.

28. Li Y-C, Bai W-Z, Hirano N, Hayashida T, Hashikawa T. Coronavirus infection of rat dorsal root ganglia: ultrastructural characterization of viral replication, transfer, and the early response of satellite cells. Virus research. 2012;163(2):628-35.

29. Buzhdygan TP, DeOre BJ, Baldwin-Leclair A, McGary H, Razmpour R, Galie $P A$, et al. The SARS-CoV-2 spike protein alters barrier function in 2D static and $3 \mathrm{D}$ microfluidic in vitro models of the human blood-brain barrier. bioRxiv. 2020

30. Lu R, Zhao X, Li J, Niu P, Yang B, Wu H, et al. Genomic characterisation and epidemiology of 2019 novel coronavirus: implications for virus origins and receptor binding. The Lancet. 2020;395(10224):565-74.

31. Wan Y, Shang J, Graham R, Baric RS, Li F. Receptor recognition by the novel coronavirus from Wuhan: an analysis based on decade-long structural studies of SARS coronavirus. Journal of virology. 2020;94(7).

32. To K, Lo AW. Exploring the pathogenesis of severe acute respiratory syndrome (SARS): the tissue distribution of the coronavirus (SARS-CoV) and its putative receptor, angiotensin-converting enzyme 2 (ACE2). The Journal of Pathology: A Journal of the Pathological Society of Great Britain and Ireland. 2004:203(3):740-3.

33. Tang JW, To KF, Lo AW, Sung JJ, Ng H, Chan PK. Quantitative temporalspatial distribution of severe acute respiratory syndrome-associated coronavirus (SARS-CoV) in post-mortem tissues. Journal of medical virology. 2007;79(9):1245-53.

34. Kam YW, Okumura Y, Kido H, Ng LFP, Bruzzone R, Altmeyer R. Cleavage of the SARS coronavirus spike glycoprotein by airway proteases enhances virus entry into human bronchial epithelial cells in vitro. PLoS One. 2009;4(11):10.

35. Mattern T, Scholz W, Feller A, Flad HD, Ulmer A. Expression of CD26 (dipeptidyl peptidase IV) on resting and activated human T-lymphocytes. Scandinavian journal of immunology. 1991;33(6):737-48.

36. Boonacker $\mathrm{E}$, Van Noorden CJ. The multifunctional or moonlighting protein CD26/DPPIV. European journal of cell biology. 2003;82(2):53-73.

37. Hoffmann M, Kleine-Weber H, Schroeder S, Kruger N, Herrler T, Erichsen S, et al. SARS-CoV-2 cell entry depends on ACE2 and TMPRSS2 and is blocked by a clinically proven protease inhibitor. Cell. 2020;181(2):271-80 e8.

38. Li W, Moore MJ, Vasilieva N, Sui J, Wong SK, Berne MA, et al. Angiotensinconverting enzyme 2 is a functional receptor for the SARS coronavirus. Nature. 2003;426(6965):450-4

39. Zhou F, Yu T, Du R, Fan G, Liu Y, Liu Z, et al. Clinical course and risk factors for mortality of adult inpatients with COVID-19 in Wuhan, China: a retrospective cohort study. The Lancet. 2020;395(10229):1054-62.

40. Zheng Y-Y, Ma Y-T, Zhang J-Y, Xie X. COVID-19 and the cardiovascular system. Nature Reviews Cardiology. 2020;17(5):259-60.

41. Turner AJ, Hiscox JA, Hooper NM. ACE2: from vasopeptidase to SARS virus receptor. Trends in pharmacological sciences. 2004;25(6):291-4.

42. Donoghue M, Hsieh F, Baronas E, Godbout K, Gosselin M, Stagliano N, et al. A novel angiotensin-converting enzyme-related carboxypeptidase (ACE2) converts angiotensin I to angiotensin 1-9. Circulation research. 2000;87(5):e1-9.

43. Harmer D, Gilbert M, Borman R, Clark KL. Quantitative mRNA expression profiling of ACE 2, a novel homologue of angiotensin converting enzyme. FEBS letters. 2002;532(1-2):107-10.

44. Hamming I, Timens W, Bulthuis M, Lely A, Navis G, van Goor H. Tissue distribution of ACE2 protein, the functional receptor for SARS coronavirus. A first step in understanding SARS pathogenesis. The Journal of Pathology: A Journal of the Pathological Society of Great Britain and Ireland. 2004;203(2):631-7.
45. Xia H, Lazartigues E. Angiotensin-converting enzyme 2 in the brain: properties and future directions. Journal of neurochemistry. 2008;107(6): 1482-94.

46. Oudit GY, Kassiri Z, Jiang C, Liu PP, Poutanen SM, Penninger JM, et al. SARScoronavirus modulation of myocardial ACE2 expression and inflammation in patients with SARS. European journal of clinical investigation. 2009;39(7): 618-25.

47. Vickers C, Hales P, Kaushik V, Dick L, Gavin J, Tang J, et al. Hydrolysis of biological peptides by human angiotensin-converting enzyme-related carboxypeptidase. J Biol Chem. 2002;277(17):14838-43.

48. Donoghue M, Hsieh F, Baronas E, Godbout K, Gosselin M, Stagliano N, et al. A novel angiotensin-converting enzyme-related carboxypeptidase (ACE2) converts angiotensin I to angiotensin 1-9. Circ Res. 2000;87(5):E1-9.

49. Tipnis SR, Hooper NM, Hyde R, Karran E, Christie G, Turner AJ. A human homolog of angiotensin-converting enzyme. Cloning and functional expression as a captopril-insensitive carboxypeptidase. J Biol Chem. 2000; 275(43):33238-43

50. Chan PK, To KF, Lo AW, Cheung J, Chu I, Au FW, et al. Persistent infection of SARS coronavirus in colonic cells in vitro. Journal of medical virology. 2004;74(1):1-7.

51. Ding $Y$, Wang $H$, Shen $H$, Li Z, Geng J, Han $H$, et al. The clinical pathology of severe acute respiratory syndrome (SARS): a report from China. The Journal of Pathology: A Journal of the Pathological Society of Great Britain and Ireland. 2003;200(3):282-9.

52. Hamming I, Timens W, Bulthuis ML, Lely AT, Navis G, van Goor H. Tissue distribution of ACE2 protein, the functional receptor for SARS coronavirus. A first step in understanding SARS pathogenesis. J Pathol. 2004;203(2):631-7.

53. Gowrisankar W, Clark MA. Angiotensin II regulation of angiotensinconverting enzymes in spontaneously hypertensive rat primary astrocyte cultures. Journal of neurochemistry. 2016;138(1):74-85.

54. Xiao L, Haack KK, Zucker $\mathrm{H}$. Angiotensin II regulates ACE and ACE2 in neurons through p38 mitogen-activated protein kinase and extracellular signal-regulated kinase 1/2 signaling. Am J Physiol Cell Physiol. 2013;304(11): C1073-9.

55. Yeh EA, Collins A, Cohen ME, Duffner PK, Faden H. Detection of coronavirus in the central nervous system of a child with acute disseminated encephalomyelitis. Pediatrics. 2004;113(1):e73-e6.

56. Hui DS, Zumla A. Severe acute respiratory syndrome: historical, epidemiologic, and clinical features. Infectious Disease Clinics. 2019;33(4): 869-89.

57. Butowt R, Bilinska K. SARS-CoV-2: Olfaction, brain infection, and the urgent need for clinical samples allowing earlier virus detection. ACS Chem Neurosci. 2020;11(9):1200-3.

58. Iwata-Yoshikawa N, Okamura T, Shimizu Y, Hasegawa H, Takeda M, Nagata N. TMPRSS2 contributes to virus spread and immunopathology in the airways of murine models after coronavirus infection. J Virol. 2019;93(6).

59. Bilinska K, Jakubowska P, Von Bartheld CS, Butowt R. Expression of the SARS-CoV-2 entry proteins, ACE2 and TMPRSS2, in cells of the olfactory epithelium: identification of cell types and trends with age. ACS Chem Neurosci. 2020;11(11):1555-62.

60. Li YC, Bai WZ, Hirano N, Hayashida T, Taniguchi T, Sugita Y, et al. Neurotropic virus tracing suggests a membranous-coating-mediated mechanism for transsynaptic communication. Journal of Comparative Neurology. 2013;521(1):203-12.

61. Matsuda K, Park C, Sunden Y, Kimura T, Ochiai K, Kida $H$, et al. The vagus nerve is one route of transneural invasion for intranasally inoculated influenza a virus in mice. Veterinary pathology. 2004;41(2):101-7.

62. Gu J, Gong E, Zhang B, Zheng J, Gao Z, Zhong Y, et al. Multiple organ infection and the pathogenesis of SARS. The Journal of experimental medicine. 2005:202(3):415-24.

63. Ding $Y$, He L, Zhang $Q$, Huang $Z$, Che $X$, Hou J, et al. Organ distribution of severe acute respiratory syndrome (SARS) associated coronavirus (SARS-CoV) in SARS patients: implications for pathogenesis and virus transmission pathways. The Journal of Pathology: A Journal of the Pathological Society of Great Britain and Ireland. 2004;203(2):622-30.

64. Xu J, Zhong S, Liu J, Li L, Li Y, Wu X, et al. Detection of severe acute respiratory syndrome coronavirus in the brain: potential role of the chemokine mig in pathogenesis. Clinical infectious diseases. 2005;41(8): 1089-96.

65. Li K, Wohlford-Lenane C, Perlman S, Zhao J, Jewell AK, Reznikov LR, et al. Middle East respiratory syndrome coronavirus causes multiple organ 
damage and lethal disease in mice transgenic for human dipeptidy peptidase 4. J Infect Dis. 2016;213(5):712-22.

66. McCray PB Jr, Pewe L, Wohlford-Lenane C, Hickey M, Manzel L, Shi L, et al. Lethal infection of K18-hACE2 mice infected with severe acute respiratory syndrome coronavirus. J Virol. 2007:81(2):813-21.

67. Netland J, Meyerholz DK, Moore S, Cassell M, Perlman S. Severe acute respiratory syndrome coronavirus infection causes neuronal death in the absence of encephalitis in mice transgenic for human ACE2. J Virol. 2008:82(15):7264-75.

68. Eliezer M, Hautefort C, Hamel AL, Verillaud B, Herman P, Houdart E, et al. Sudden and complete olfactory loss function as a possible symptom of COVID-19. JAMA Otolaryngol Head Neck Surg. 2020.

69. Hwang C. Olfactory neuropathy in severe acute respiratory syndrome: report of a case. Acta Neurologica Taiwanica. 2006;15(1):26.

70. Xydakis MS, Dehgani-Mobaraki P, Holbrook EH, Geisthoff UW, Bauer C, Hautefort C, et al. Smell and taste dysfunction in patients with COVID-19. Lancet Infect Dis. 2020.

71. Pleasure SJ, Green AJ, Josephson SA. The spectrum of neurologic disease in the severe acute respiratory syndrome coronavirus 2 pandemic infection: neurologists move to the frontlines. JAMA neurology. 2020;77(6):679-80.

72. Burgueno JF, Reich A, Hazime H, Quintero MA, Fernandez I, Fritsch J, et al. Expression of SARS-CoV-2 entry molecules ACE2 and TMPRSS2 in the gut of patients with IBD. Inflamm Bowel Dis. 2020;26(6):797-808.

73. Lin L, Jiang X, Zhang Z, Huang S, Zhang Z, Fang Z, et al. Gastrointestinal symptoms of 95 cases with SARS-CoV-2 infection. Gut. 2020;69(6):997-1001.

74. Bostanciklioglu M. Temporal correlation between neurological and gastrointestinal symptoms of SARS-CoV-2. Inflamm Bowel Dis. 2020;26(8):e89-91.

75. Brann DH, Tsukahara T, Weinreb C, Lipovsek M, Van den Berge K, Gong B, et al. Non-neuronal expression of SARS-CoV-2 entry genes in the olfactory system suggests mechanisms underlying COVID-19-associated anosmia. Sci Adv. 2020

76. Chen M, Reed RR, Lane AP. Chronic inflammation directs an olfactory stem cell functional switch from neuroregeneration to immune defense. Cell Stem Cell. 2019;25(4):501-13 e5.

77. Plasschaert LW, Zilionis R, Choo-Wing R, Savova V, Knehr J, Roma G, et al. A single-cell atlas of the airway epithelium reveals the CFTR-rich pulmonary ionocyte. Nature. 2018:560(7718):377-81.

78. Bihun CG, Percy DH. Morphologic changes in the nasal cavity associated with sialodacryoadenitis virus infection in the Wistar rat. Vet Pathol. 1995; 32(1):1-10.

79. Katze MG, He Y, Gale M Jr. Viruses and interferon: a fight for supremacy. Nat Rev Immunol. 2002;2(9):675-87.

80. Kawai T, Akira S. Innate immune recognition of viral infection. Nat Immunol. 2006;7(2):131-7.

81. Garcia-Sastre A, Biron CA. Type 1 interferons and the virus-host relationship: a lesson in detente. Science. 2006;312(5775):879-82.

82. Channappanavar R, Fehr AR, Vijay R, Mack M, Zhao J, Meyerholz DK, et al. Dysregulated type I interferon and inflammatory monocyte-macrophage responses cause lethal pneumonia in SARS-CoV-infected mice. Cell host \& microbe. 2016;19(2):181-93.

83. Chen G, Wu D, Guo W, Cao Y, Huang D, Wang H, et al. Clinical and immunological features of severe and moderate coronavirus disease 2019. The Journal of clinical investigation. 2020;130(5):2620-9.

84. Pedersen SF, Ho YC. SARS-CoV-2: a storm is raging. The Journal of clinical investigation. 2020;130(5):2202-5.

85. Diao B, Wang C, Tan Y, Chen X, Liu Y, Ning L, et al. Reduction and functional exhaustion of T cells in patients with coronavirus disease 2019 (COVID-19). Front Immunol. 2020;11:827.

86. Mehta P, McAuley DF, Brown M, Sanchez E, Tattersall RS, Manson JJ, et al. COVID-19: consider cytokine storm syndromes and immunosuppression. Lancet. 2020;395(10229):1033-4.

87. Mehta P, McAuley DF, Brown M, Sanchez E, Tattersall RS, Manson JJ. COVID19: consider cytokine storm syndromes and immunosuppression. The Lancet. 2020;395(10229):1033-4.

88. Vaibhav K, Braun M, Khan MB, Fatima S, Saad N, Shankar A, et al. Remote ischemic post-conditioning promotes hematoma resolution via AMPKdependent immune regulation. J Exp Med. 2018;215(10):2636-54.

89. Braun M, Khan ZT, Khan MB, Kumar M, Ward A, Achyut BR, et al. Selective activation of cannabinoid receptor-2 reduces neuroinflammation after traumatic brain injury via alternative macrophage polarization. Brain, behavior, and immunity. 2018;68:224-37.
90. Braun M, Vaibhav K, Saad N, Fatima S, Brann DW, Vender JR, et al. Activation of myeloid TLR4 mediates T lymphocyte polarization after traumatic brain injury. Journal of immunology. 2017;198(9):3615-26.

91. Braun M, Vaibhav K, Saad NM, Fatima S, Vender JR, Baban B, et al. White matter damage after traumatic brain injury: a role for damage associated molecular patterns. Biochimica et biophysica acta Molecular basis of disease. 2017;1863(10 Pt B):2614-26.

92. Poyiadji N, Shahin G, Noujaim D, Stone M, Patel S, Griffith B. COVID-19associated acute hemorrhagic necrotizing encephalopathy: imaging features. Radiology. 2020;296(2):E119-E20.

93. Wong AM, Simon EM, Zimmerman RA, Wang HS, Toh CH, Ng SH. Acute necrotizing encephalopathy of childhood: correlation of MR findings and clinical outcome. AJNR Am J Neuroradiol. 2006;27(9):1919-23.

94. Raabe A, Wissing H, Zwissler B. Brain cell damage and S-100B increase after acute lung injury. Anesthesiology: The Journal of the American Society of Anesthesiologists. 2005;102(4):713-4.

95. Pelosi P, Rocco PR. The lung and the brain: a dangerous cross-talk. Critical care. 2011;15(3):168.

96. Na B, Zhang H, Wang G, Dai L, Xia G. The effect of mechanical ventilation on TASK-1 expression in the brain in a rat model. Canadian respiratory journal. 2017;2017:8530352.

97. Della Torre V, Badenes R, Corradi F, Racca F, Lavinio A, Matta B, et al. Acute respiratory distress syndrome in traumatic brain injury: how do we manage it? Journal of thoracic disease. 2017;9(12):5368-81.

98. Lester SN, Li K. Toll-like receptors in antiviral innate immunity. J Mol Biol. 2014;426(6):1246-64.

99. Alexopoulou L, Holt AC, Medzhitov R, Flavell RA. Recognition of doublestranded RNA and activation of NF-kappaB by Toll-like receptor 3. Nature. 2001;413(6857):732-8.

100. Zhao J, Wohlford-Lenane C, Zhao J, Fleming E, Lane TE, McCray PB Jr, et al. Intranasal treatment with poly $\left({ }^{*} \mathrm{C}\right)$ protects aged mice from lethal respiratory virus infections. J Virol. 2012;86(21):11416-24.

101. Kumaki Y, Salazar AM, Wandersee MK, Barnard DL. Prophylactic and therapeutic intranasal administration with an immunomodulator, Hiltonol((R)) (Poly IC:LC), in a lethal SARS-CoV-infected BALB/C mouse model. Antiviral Res. 2017;139:1-12.

102. Ngoi SM, Tovey MG, Vella AT. Targeting poly(l:C) to the TLR3-independent pathway boosts effector CD8 T cell differentiation through IFN-alpha/beta. Journal of immunology. 2008;181(11):7670-80.

103. Qin L, Crews FT. Chronic ethanol increases systemic TLR3 agonist-induced neuroinflammation and neurodegeneration. J Neuroinflammation. 2012;9:130.

104. Lodigiani C, lapichino G, Carenzo L, Cecconi M, Ferrazzi P, Sebastian T, et al. Venous and arterial thromboembolic complications in COVID-19 patients admitted to an academic hospital in Milan. Italy. Thromb Res. 2020;191:9-14.

105. Helms J, Tacquard C, Severac F, Leonard-Lorant I, Ohana M, Delabranche X, et al. High risk of thrombosis in patients with severe SARS-CoV-2 infection: a multicenter prospective cohort study. Intensive Care Med. 2020;46(6):1089-98.

106. Kollias A, Kyriakoulis KG, Dimakakos E, Poulakou G, Stergiou GS, Syrigos K. Thromboembolic risk and anticoagulant therapy in COVID-19 patients: emerging evidence and call for action. Br J Haematol. 2020;189(5):846-7.

107. Connors JM, Levy JH. COVID-19 and its implications for thrombosis and anticoagulation. Blood. 2020;135(23):2033-40.

108. Milbrandt EB, Reade MC, Lee M, Shook SL, Angus DC, Kong L, et al. Prevalence and significance of coagulation abnormalities in communityacquired pneumonia. Molecular Medicine. 2009;15(11-12):438-45.

109. Tang N, Bai H, Chen X, Gong J, Li D, Sun Z. Anticoagulant treatment is associated with decreased mortality in severe coronavirus disease 2019 patients with coagulopathy. J Thromb Haemost. 2020;18(5):1094-9.

110. Gupta $N$, Zhao $Y Y$, Evans CE. The stimulation of thrombosis by hypoxia. Thromb Res. 2019;181:77-83.

111. Deliwala S, Abdulhamid S, Abusalih MF, Al-Qasmi MM, Bachuwa G. Encephalopathy as the sentinel sign of a cortical stroke in a patient infected with coronavirus disease-19 (COVID-19). Cureus. 2020;12(5):e8121.

112. Goldberg MF, Goldberg MF, Cerejo R, Tayal AH. Cerebrovascular disease in COVID-19. AJNR Am J Neuroradiol. 2020;41(7):1170-2.

113. Levi M, van der Poll T. Inflammation and coagulation. Crit Care Med. 2010; 38(2 Suppl):S26-34.

114. Siniscalchi A, Gallelli L. Could COVID-19 represent a negative prognostic factor in patients with stroke? Infect Control Hosp Epidemiol. 2020;1. 
115. Siniscalchi A, Gallelli L, Malferrari G, Pirritano D, Serra R, Santangelo E, et al. Cerebral stroke injury: the role of cytokines and brain inflammation. J Basic Clin Physiol Pharmacol. 2014;25(2):131-7.

116. Siniscalchi A, lannacchero R, Anticoli S, Pezzella FR, De Sarro G, Gallelli L. Anti-inflammatory strategies in stroke: a potential therapeutic target. Curr Vasc Pharmacol. 2016;14(1):98-105.

117. Consoli D, Vidale S, Aguglia U, Bassi P, Cavallini A, Galati F, et al. Previous infection and the risk of ischaemic stroke in Italy: the IN2 study. Eur J Neurol. 2015;22(3):514-9.

118. Liu Y, Du X, Chen J, Jin Y, Peng L, Wang HHX, et al. Neutrophil-tolymphocyte ratio as an independent risk factor for mortality in hospitalized patients with COVID-19. J Infect. 2020;81(1):e6-e12

119. Sun S, Cai X, Wang H, He G, Lin Y, Lu B, et al. Abnormalities of peripheral blood system in patients with COVID-19 in Wenzhou. China. Clin Chim Acta. 2020;507:174-80.

120. Yan X, Li F, Wang X, Yan J, Zhu F, Tang S, et al. Neutrophil to lymphocyte ratio as prognostic and predictive factor in patients with coronavirus disease 2019: a retrospective cross-sectional study. J Med Virol. 2020.

121. Barnes BJ, Adrover JM, Baxter-Stoltzfus A, Borczuk A, Cools-Lartigue J, Crawford JM, et al. Targeting potential drivers of COVID-19: neutrophil extracellular traps. J Exp Med. 2020;217(6).

122. Yao X, Li T, He Z, Ping Y, Liu H, Yu S, et al. A pathological report of three COVID-19 cases by minimally invasive autopsies. Zhonghua bing li xue za zhi=Chinese journal of pathology. 2020;49:E009-E.

123. Wu P, Duan F, Luo C, Liu Q, Qu X, Liang L, et al. Characteristics of ocular findings of patients with coronavirus disease 2019 (COVID-19) in Hubei Province. China. JAMA Ophthalmol. 2020;138(5):575-8.

124. Fox SE, Akmatbekov A, Harbert JL, Li G, Quincy Brown J, Vander Heide RS. Pulmonary and cardiac pathology in African American patients with COVID19: an autopsy series from New Orleans. Lancet Respir Med. 2020;8(7):681-6.

125. Magro C, Mulvey JJ, Berlin D, Nuovo G, Salvatore S, Harp J, et al. Complement associated microvascular injury and thrombosis in the pathogenesis of severe COVID-19 infection: a report of five cases. Transl Res. 2020;220:1-13.

126. Sabbione F, Keitelman IA, Iula L, Ferrero M, Giordano MN, Baldi P, et al. Neutrophil extracellular traps stimulate proinflammatory responses in human airway epithelial cells. J Innate Immun. 2017;9(4): 387-402.

127. Barnes BJ, Adrover JM, Baxter-Stoltzfus A, Borczuk A, Cools-Lartigue J, Crawford JM, et al. Targeting potential drivers of COVID-19: neutrophil extracellular traps. Journal of Experimental Medicine. 2020;217(6).

128. Porto BN, Stein RT. Neutrophil extracellular traps in pulmonary diseases: too much of a good thing?, Front Immunol. 2016;7:311.

129. Li H, Zhou X, Tan H, Hu Y, Zhang L, Liu S, et al. Neutrophil extracellular traps contribute to the pathogenesis of acid-aspiration-induced ALI/ARDS. Oncotarget. 2017;9(2):1772-84.

130. Mikacenic C, Moore R, Dmyterko V, West TE, Altemeier WA, Liles WC, et al. Neutrophil extracellular traps (NETs) are increased in the alveolar spaces of patients with ventilator-associated pneumonia. Critical Care. 2018;22(1):358

131. Sorvillo N, Cherpokova D, Martinod K, Wagner DD. Extracellular DNA NETWorks with dire consequences for health. Circulation Research. 2019;125(4): 470-88.

132. Caudrillier A, Kessenbrock K, Gilliss BM, Nguyen JX, Marques MB, Monestier $\mathrm{M}$, et al. Platelets induce neutrophil extracellular traps in transfusion-related acute lung injury. The Journal of clinical investigation. 2012;122(7):2661-71.

133. Adrover JM, Aroca-Crevillén A, Crainiciuc G, Ostos F, Rojas-Vega Y, RubioPonce A, et al. Programmed 'disarming' of the neutrophil proteome reduces the magnitude of inflammation. Nature Immunology. 2020:1-10.

134. Bendib I, de Chaisemartin L, Granger V, Schlemmer F, Maitre B, Hüe S, et al. Neutrophil extracellular traps are elevated in patients with pneumoniarelated acute respiratory distress syndrome. Anesthesiology: The Journal of the American Society of Anesthesiologists. 2019;130(4):581-91.

135. Ebrahimi F, Giaglis S, Hahn S, Blum CA, Baumgartner C, Kutz A, et al. Markers of neutrophil extracellular traps predict adverse outcome in communityacquired pneumonia: secondary analysis of a randomised controlled trial. European respiratory journal. 2018;51(4).

136. Lefrançais E, Mallavia B, Zhuo H, Calfee CS, Looney MR. Maladaptive role of neutrophil extracellular traps in pathogen-induced lung injury. JCl insight. 2018;3(3).
137. Zuo Y, Yalavarthi S, Shi H, Gockman K, Zuo M, Madison JA, et al. Neutrophil extracellular traps in COVID-19. JCI Insight. 2020;5(11).

138. Fuchs TA, Brill A, Duerschmied D, Schatzberg D, Monestier M, Myers DD Jr, et al. Extracellular DNA traps promote thrombosis. Proc Natl Acad Sci U S A. 2010;107(36):15880-5.

139. Jimenez-Alcazar M, Rangaswamy C, Panda R, Bitterling J, Simsek YJ, Long AT, et al. Host DNases prevent vascular occlusion by neutrophil extracellular traps. Science. 2017;358(6367):1202-6.

140. Jimenez-Alcazar M, Napirei M, Panda R, Kohler EC, Kremer Hovinga JA, Mannherz HG, et al. Impaired DNase1-mediated degradation of neutrophil extracellular traps is associated with acute thrombotic microangiopathies. J Thromb Haemost. 2015;13(5):732-42.

141. Valles J, Lago A, Santos MT, Latorre AM, TembI Jl, Salom JB, et al. Neutrophil extracellular traps are increased in patients with acute ischemic stroke: prognostic significance. Thromb Haemost. 2017;117(10):1919-29.

142. Laridan E, Denorme F, Desender L, Francois O, Andersson T, Deckmyn H, et al. Neutrophil extracellular traps in ischemic stroke thrombi. Ann Neurol. 2017;82(2):223-32.

143. Vaibhav K, Braun M, Alverson K, Khodadadi H, Kutiyanawalla A, Ward A, et al. Neutrophil extracellular traps exacerbate neurological deficits after traumatic brain injury. Sci Adv. 2020;6:eaax8847.

144. Earhart AP, Holliday ZM, Hofmann HV, Schrum AG. Consideration of dornase alfa for the treatment of severe COVID-19 acute respiratory distress syndrome. New Microbes New Infect. 2020;35:100689.

145. De Meyer SF, Suidan GL, Fuchs TA, Monestier M, Wagner DD. Extracellular chromatin is an important mediator of ischemic stroke in mice. Arterioscler Thromb Vasc Biol. 2012;32(8):1884-91.

146. Pena-Martinez C, Duran-Laforet V, Garcia-Culebras A, Ostos F, HernandezJimenez M, Bravo-Ferrer I, et al. Pharmacological modulation of neutrophil extracellular traps reverses thrombotic stroke tPA (Tissue-Type Plasminogen Activator) resistance. Stroke. 2019;50(11):3228-37.

147. Ducroux C, Di Meglio L, Loyau S, Delbosc S, Boisseau W, Deschildre C, et al. Thrombus neutrophil extracellular traps content impair tPA-induced thrombolysis in acute ischemic stroke. Stroke. 2018:49(3):754-7.

148. Siddiqi HK, Mehra MR. COVID-19 illness in native and immunosuppressed states: a clinical-therapeutic staging proposal. J Heart Lung Transplant. 2020; 39(5):405-7.

149. Maxwell NM, Nevin RL, Stahl S, Block J, Shugarts S, Wu AH, et al. Prolonged neuropsychiatric effects following management of chloroquine intoxication with psychotropic polypharmacy. Clin Case Rep. 2015;3(6):379-87.

150. Bridwell R, Long B, Gottlieb M. Neurologic complications of COVID-19. Am J Emerg Med. 2020;38(7):1549 e3-7.

151. Niazkar HR, Zibaee B, Nasimi A, Bahri N. The neurological manifestations of COVID-19: a review article. Neurol Sci. 2020;41(7):1667-71.

152. Simonnet A, Chetboun M, Poissy J, Raverdy V, Noulette J, Duhamel A, et al. High prevalence of obesity in severe acute respiratory syndrome coronavirus-2 (SARS-CoV-2) requiring invasive mechanical ventilation. Obesity (Silver Spring). 2020;28(7):1195-9.

153. Nakeshbandi M, Maini R, Daniel P, Rosengarten S, Parmar P, Wilson C, et al. The impact of obesity on COVID-19 complications: a retrospective cohort study. Int J Obes (Lond). 2020;44(9):1832-7.

154. Malik VS, Ravindra K, Attri SV, Bhadada SK, Singh M. Higher body mass index is an important risk factor in COVID-19 patients: a systematic review and meta-analysis. Environ Sci Pollut Res Int. 2020.

155. Apicella M, Campopiano MC, Mantuano M, Mazoni L, Coppelli A, Del Prato S. COVID-19 in people with diabetes: understanding the reasons for worse outcomes. Lancet Diabetes Endocrinol. 2020;8(9):782-92.

156. International MGC-WG, Jacob S, Muppidi S, Guidon A, Guptill J, Hehir M, et al. Guidance for the management of myasthenia gravis (MG) and Lambert-Eaton myasthenic syndrome (LEMS) during the COVID-19 pandemic. J Neurol Sci. 2020;412:116803.

157. Delly F, Syed MJ, Lisak RP, Zutshi D. Myasthenic crisis in COVID-19. J Neurol Sci. 2020;414:116888

158. Barzegar M, Mirmosayyeb O, Nehzat N, Sarrafi R, Khorvash F, Maghzi AH, et al. COVID-19 infection in a patient with multiple sclerosis treated with fingolimod. Neurol Neuroimmunol Neuroinflamm. 2020;7(4).

159. Berger JR, Brandstadter R, Bar-Or A. COVID-19 and MS disease-modifying therapies. Neurol Neuroimmunol Neuroinflamm. 2020;7(4).

160. Maguire C, Frohman T, Zamvil SS, Frohman E, Melamed E. Should interferons take front stage as an essential MS disease-modifying therapy in 
the era of coronavirus disease 2019? Neurol Neuroimmunol Neuroinflamm. 2020;7(5).

161. Rogers JP, Chesney E, Oliver D, Pollak TA, McGuire P, Fusar-Poli P, et al. Psychiatric and neuropsychiatric presentations associated with severe coronavirus infections: a systematic review and meta-analysis with comparison to the COVID-19 pandemic. The lancet Psychiatry. 2020;7(7): $611-27$

\section{Publisher's Note}

Springer Nature remains neutral with regard to jurisdictional claims in published maps and institutional affiliations.

Ready to submit your research? Choose BMC and benefit from:

- fast, convenient online submission

- thorough peer review by experienced researchers in your field

- rapid publication on acceptance

- support for research data, including large and complex data types

- gold Open Access which fosters wider collaboration and increased citations

- maximum visibility for your research: over $100 \mathrm{M}$ website views per year

At BMC, research is always in progress.

Learn more biomedcentral.com/submissions 